\title{
Comunicação e Agenda 21: o caso de Ilhéus, Bahia*
}

\section{Anaelson Leandro de Sousa * *}

\section{Resumo}

A Conferência das Nações Unidas sobre o Meio Ambiente e Desenvolvimento, realizada em junho de 1992, conhecida também como RIO-92, aprovou acordos importantes, dentre eles a Agenda 21. A Agenda é uma carta de compromissos, visando o desenvolvimento sustentável, elaborada nos âmbitos federal, estadual e-municipal, entre governo e sociedade. Em Ilhéus, região sul do estado da Bahia, a elaboração da Agenda 21 começou a ser discutida no final de 1997, tendo a sua conclusão ocorrido em setembro de 1998. O objetivo deste trabalho é analisar qualitativamente o texto da Agenda 21 de Ilhéus, buscando identificar os problemas e as soluções propostas, relacionadas à Comunicação Social.

Palavras-chave: comunicação; meio ambiente; agenda 21.

\section{Comunicação e Meio Ambiente}

No Brasil, traçando um histórico dos meios de comunicação como meio mobilizador e formulador de opinião pública ambiental, Viola (1992) explica que na década de 60, mesmo com as primeiras iniciativas das organizações ambientais no país, não existia sequer uma preocupação marginal com a problemática ambiental na opinião pública. Nem a Conferência de Estocolmo, em 1972, foi capaz de gerar um debate amplo na sociedade brasileira.

* O paper corresponde a estudos iniciais da dissertação de mestrado "Comunicação e Meio Ambiente: o Jornalismo na construção e execução da Agenda 21 de Ilhéus, Bahia", do Programa Regional de Pós-graduação em Desenvolvimento e Meio Ambiente - PRODEMA, co-orientado pelo Dr. André Belém.

** Jornalista, Mestrando em Desenvolvimento Regional e Meio Ambiente PRODEMA/UESC e Professor do curso de Comunicação Social da UESC.

Comun. Inf., v. 6, n. 2, p.62-74, jul./dez. 2003 
Somente no final dos anos 70 e início de 80 , com a multiplicação de grupos ambientais, principalmente em cidades das regiões Sul e Sudeste, é que a opinião pública começa a se manifestar diante da problemática do meio ambiente, como foi o caso da extrema deterioração sócioambiental em Cubatão/SP.1987, o documento não repercutiu nos meios de comunicação de maneira satisfatória a mobilizar Ainda nos anos 80 , outro momento marcante da história ambiental foi a elaboração do relatório Nosso Futuro Comum, conhecido também como Relatório Brundtland. Concluído em a sociedade para uma discussão local, serviu para alertar sobre a escassez de recursos naturais e a necessidade de repensar os novos significados de desenvolvimento, conforme STARKE.

\begin{abstract}
"Apesar do Relatório Brundtland não ter tido efeitos diretos nos meios de comunicação, seu impacto indireto decorre de ter levado o desenvolvimento sustentável ao cenário internacional e à pauta de diversas reuniões cobertas pela mídia (...) A cobertura só foi sofisticada à medida que se evidenciava 0 fato de não haver soluções simples para problemas globais e locais de desenvolvimento" (1991, p. 136).
\end{abstract}

Após a realização da duas últimas grandes Conferências, realizadas no Rio de Janeiro, RIO-92, e em Johannesburgo, África do Sul, cunhada como RIO +10, o debate sobre o papel dos meios de comunicação vem sendo ampliado cada vez mais - como exemplo, o Encontro Imprensa Verde 2, também chamado de Green Press 2, realizado em Belo Horizonte, em 18 e 19 de novembro de 2002, com o objetivo de discutir o objetivo da mídia após a RIO +10. As discussões giraram em torno da posição dos jornalistas diante dos desafios para aumentar a consciência ecológica mundial (Gorgulho, 2002, p.14).

A preocupação em estabelecer vias de mão dupla quanto à comunicação tem sido recíproca tanto no campo do jornalismo como das Organizações Não-Governamentais - ONGs, principalmente após a realização da RIO-92. No campo das ONGs, Castells observa que o movimento ambientalista e a sua relação com o conjunto de meios de comunicação, muitas vezes, são os principais meios responsáveis pela mobilização ambiental:

Comun. Inf., v. 6, n. 2, p.62-74, jul./dez. 2003 
"Contudo a ação do movimento também é o cotidiano das lutas ambientalistas em nível local. Noticiários de TV, rádio e jornais são instrumentos de divulgação dos ambientalistas, a ponto de existirem reclamações por parte dos políticos e das grandes corporações de que é a mídia e não os ambientalistas, a grande responsável pela mobilização em torno da questão ambiental" (1999, p.161).

Quanto à prática, o Jornalismo Ambiental ainda sofre críticas sobre a sua verdadeira relação com a notícia. Segundo Villar, a imprensa brasileira dificilmente trata dos problemas ambientais com profundidade na pauta das discussões públicas. As exceções são frutos de um esforço pessoal e isolado. O meio ambiente ganha espaço (jornal impresso) e tempo (rádio e TV) na cobertura diária quando acontecem desastres ou quando os assuntos repercutem no exterior, como a morte de um ecologista famoso, as queimadas e os desmatamentos na Amazônia e na Mata Atlântica.

O pós-RIO-92 contribuiu também para o crescimento no campo da pesquisa em Comunicação e Meio Ambiente, no qual muitos estudos têm contribuído para dar luzes ao assunto, fato comprovado com as publicações dos trabalhos de Ramos (1995), Kunsch e Dencker (1996), Ungaretti (1998), Barros (2001), Rabelo (2003), dentre outros resultantes de pesquisa acadêmica.

Considerando que a mídia permeia todo o tecido social e pode funcionar como veículo de educação ambiental na sociedade, torna-se imprescindível aprofundar de maneira mais eficaz a sua relação com o meio ambiente. Ramos, analisando a influência da comunicação no discurso ambiental, afirma que ao mesmo tempo em que cumpre o papel de elemento de ligação para a constituição de uma base de entendimento comum diante das diferentes leituras sobre o ambiente, a comunicação de massa é responsável tanto pela omissão quanto pela difusão indiscriminada de mensagens ambientais. Eque muitas dessas mensagens refletem interesses meramente corporativos, e não coletivos, uma vez que meio ambiente engloba toda a coletividade (1995, p. 30).

Independentemente da condição de controle da informação que a mídia assume é necessário mudar essa concepção centralizadora, permitindo à sociedade uma visão ampla sobre o meio ambiente. Segundo Timberlake, um dos participantes do relatório Nosso Futuro Comum, a problemática ambiental deve ser entendida de maneira

Comun. Inf., v. 6, n. 2, p.62-74, jul./dez. 2003 
multidisciplinar. Para ele, é preciso tirar o meio ambiente do gueto. É necessário que os repórteres falem das causas e/ou implicações ambientais em qualquer assunto que estiverem cobrindo (Timberlake, apud Starke, 1992).

Nesse sentido, reconhecendo-se a importância do jornalismo no agendamento dos problemas ecológicos e na busca de soluções, e levando-se em conta os esforços para a superação das falhas apontadas, parece oportuno ressaltar o papel que a mídia - conjunto de meios - pode desempenhar na informação e educação ambiental.

\section{Agenda 21}

A primeira grande Conferência das Nações Unidas sobre Meio Ambiente e Desenvolvimento-CNUMAD ocorreu em Estocolmo, em 1972, quando o ambientalismo era evidenciado de forma bissetorial (grupos de base e agências estatais). A segunda grande Conferência foi realizada no Rio de janeiro, em junho de 1992, e além de envolver os dois primeiros setores ambientais, mobilizou outros seis 6 (socioambiental, religioso, empresarial, e de cientistas, políticos profissionais, educadores, jornalistas e artistas), dando uma característica multissetorial ao ambientalismo (Leis, 1995).

Além da característica multissetorial da Conferência do Rio de Janeiro, também conhecida como RIO-92, o encontro mundial serviu para aprovar acordos fundamentais para implantar o desenvolvimento sustentável, como a Declaração do Rio de Janeiro sobre Meio Ambiente e Desenvolvimento, a Carta da Terra, a Declaração de Princípios para a Administração Sustentável das Florestas, e a Agenda 21 Global. O mais importante compromisso firmado durante o encontro foi a Agenda 21: um abrangente programa de ação, com a finalidade de dar efeito prático aos princípios aprovados na Declaração do Rio e que deve ser implementada pelos governos, agências de desenvolvimento, organizações das Nações Unidas e grupos setoriais independentes, em todas as áreas afetadas pelo meio ambiente, a partir de seu lançamento em 14 de junho de 1992 prolongando-se pelo século 21. Ao todo, o documento contém mais de 2.500 recomendações, divididas em 40 capítulos.

A proposta da Agenda 21 surgiu bem antes da RIO-92. Em 12 de novembro de 1990, o diplomata Maurice Strong, designado Secretário-Geral da Conferência, anunciou, na Assembléia Geral das Nações

Comun. Inf., v. 6, n. 2, p.62-74, jul./dez. 2003 
Unidas, os possíveis resultados do encontro, adiantando, assim, a proposta de uma agenda global que objetivasse reduzir a crise ambiental, tendo suas propostas voltadas para a sustentabilidade. A elaboração de uma agenda de ação conteria medidas concretas, integradas a um programa de trabalho internacionalmente acordado para o período entre a Conferência e o século XXI. Os meios necessários para a implementação da proposta deveriam enfocar recursos novos e adicionais para os países em desenvolvimento; acesso dos países em desenvolvimento a tecnologias ambientais saudáveis; e fortalecimento das instituições dedicadas ao meio ambiente e dos órgãos ambientais em agências e instituições de desenvolvimento (Ramos, 1995).

A Agenda 21 consolidou a idéia de que o desenvolvimento e a conservação do meio ambiente são imprescindíveis para o desenvolvimento sustentável e de que o os governos, em todos os âmbitos, devem ter a responsabilidade de convocar a sociedade para um amplo debate de seus problemas, que indiquem soluções a longo, médio e curto prazos.

No Brasil, foi instituída a Comissão de Políticas de Desenvolvimento Sustentável e da Agenda 21 e, a partir das discussões em seminários e workshops, no início de 1999, foi montado o livro Subsídios à Elaboração da Agenda 21 Brasileira, publicado pelo Ministério do Meio Ambiente, em 2000, enfocando os temas: Agricultura Sustentável, Cidades Sustentáveis, Infra-estrutura e Integração Regional, Gestão de Recursos Naturais, Redução de Desigualdades Sociais, e Ciência e Tecnologia para o Desenvolvimento Sustentável.

Segundo dados do MMA - Ministério do Meio Ambiente, o processo de consulta nacional desencadeado pela CPDS - Comissão de Políticas de Desenvolvimento Sustentável e da Agenda 21, entre 1999 e 2001, abrangeu 6.000 representantes de várias instituições e cerca de 40 mil pessoas foram envolvidas em todo o Brasil.

No caso da Bahia, o Governo do Estado, desde o início de 1991, antes da realização da ECO 92, já se preocupava em inovar a gestão ambiental e conscientizar os principais atores sociais e econômicos, mobilizando-os para o desenvolvimento baseado em sustentabilidade. Não obstante, a elaboração da Agenda 21, como documento elaborado junto com a sociedade civil, foi proposta pelo Centro de Recursos Ambientais ao Conselho Estadual de Meio Ambiente - CEPRAM, no mês de março de 97.

Comun. Inf., v. 6, n. 2, p.62-74, jul./dez. 2003 
Tendo em vista as diretrizes para o desenvolvimento sustentável do Estado e dando prosseguimento à implementação das recomendações da II Conferência Mundial do Meio Ambiente - ECO 92, o Governo da Bahia criou, mediante o Decreto n. ${ }^{\circ} 6.545$, de 18 de julho de 1997, a Comissão Estadual para a Agenda 21. A Comissão foi constituída para elaborar, acompanhar e avaliar a implementação das proposições, incorporando as iniciativas já em curso no Estado, competindolhe propor temário, coordenar e estimular a discussão de temas com os vários segmentos da sociedade civil e instâncias públicas.

Concomitante à elaboração da agenda estadual, em Ilhéus/BA, a primeira iniciativa em discutir o assunto ocorreu em 4 de dezembro de 1997, durante o workshop "Política de Desenvolvimento Sustentável", que serviu de base para a mobilização local. Em seguida, foi constituída, pelo Decreto Municipal n. ${ }^{\circ}$ 010/98, de 06 de janeiro de 1998, uma comissão para coordenar o processo de elaboração da Agenda 21 de Ilhéus. Em 5 de março de 1998, foi nomeada uma comissão composta por 16 membros, do Governo Municipal e da sociedade civil local, conforme o Decreto Municipal 016/98. A coordenação geral ficou por conta da Universidade Livre do Mar e da Mata Maramata e os grupos de trabalho foram divididos em: Organização Social, Educação, Saúde, Cultura, Desenvolvimento Urbano, geração de Ocupação e Renda, Turismo, Degradação Ambiental e Segurança Pública. A Agenda foi entregue à sociedade ilheense em setembro de 1998. Em 2000, foi proposta sua revisão, por alunos do Mestrado em Desenvolvimento Regional e Meio Ambiente da Universidade Estadual de Santa Cruz - UESC e pela professora de Educação Ambiental, Denise Homem Del Rey. A proposta de revisão foi deliberada pelo Conselho de Defesa do Meio Ambiente do Município de Ilhéus Condema e em 20 de fevereiro de 2001 foram concluídos os trabalhos. "As maiores alterações ocorreram nos eixos temáticos, que foram acrescidos de mais um, o Desenvolvimento Rural, além de um rol de objetivos inexistentes na proposta original..." (GMI, 2002).

\section{Comunicação e Agenda 21 de Ilhéus/BA}

De maneira geral, tentando relacionar a Agenda 21 com a comunicação, Ramos analisou as notícias ambientais antes, durante e após a RIO-92 e chegou ao seguinte dado, importante para a nossa reflexão: no jornalismo impresso, em pesquisa aplicada aos jornais Folha de $S$.

Comun. Inf., v. 6, n. 2, p.62-74, jul./dez. 2003 
Paulo e Estadão, o tema foi classificado no grupo de notícias que ocupou somente $1,5 \%$ de todo material analisado, mesmo sendo a Agenda o mais importante documento da RIO-92 (1995, p. 63). Em outra pesquisa, Barros identificou como a revista Veja tratou o tema:

\begin{abstract}
"A Agenda 21 é comentada pela revista da seguinte forma: 'na celebração da Eco 92, vai aparecer o ecologista do século XXI, que deixa o mico-leão de lado para falar do que interessa'. E mais: 'depois da reunião (...), o mundo terá motivos para se olhar de um modo diferente'(A agenda do futuro, Veja, jun. 1992), A agenda em si é ignorada pelo periódico. E, mais uma vez, repete-se o tom de ironia com os ambientalistas: ' ... e os ecologistas já sonham com sua grande oportunidade de deitar e rolar. Serão $10 \mathrm{mil}$, talvez $15 \mathrm{mil}$ militantes, misturados com índios, feministas, religiosos, seringueiros, cientistas e os desocupados de sempre" (2001).
\end{abstract}

Outro exemplo do tratamento da imprensa sobre a Agenda 21 é ilustrada em matéria publicada no jornal Gazeta Mercantil, com o título "ONGs afirmam que governos adotaram, mas não assumiram a Agenda 21 ", em $1^{\circ}$ de junhos de 1993. A informar que para o Centro Nosso Futuro Comum, uma das maiores ONGs do mundo, com sede em Genebra, responsável pelo Fórum Global da ECO 92, continuava existindo uma distância entre o discurso governamental e o efetivo cumprimento da Agenda 21, lista os princípios adotados pelos países de comum acordo (Adeodato apud Ungaretti).

Os exemplos demostram que o tema não aparece muito nos principais meios de comunicação de circulação nacional. No caso de Ilhéus, o espaço ocupado na mídia não é muito diferente do exposto até o momento.

Um dos problemas apresentados na Agenda 21 de Ilhéus, que chama a atenção para nossa proposta de estudo, está relacionado com a comunicação, principalmente no grupo de trabalho que tratou da Organização Social. O grupo relacionou diversos problemas decorrentes da relação comunicação e meio ambiente. Antes, porém, de observar mais detalhadamente as questões pertinentes é necessário entender como estão relacionados Meio Ambiente, Comunicação e Agenda 21.

Em todos os documentos relacionados à Agenda 21 é visível a preocupação ambiental nos meios de comunicação de massa, no sentido de levar o tema para a esfera pública por meio de seus veículos,

Común. Inf., v. 6, n. 2, p.62-74, jul./dez. 2003 
principalmente os meios impressos. Não é por acaso que a Agenda 21 global dedica o seu último capítulo ao assunto e propõe medidas e recursos para incentivar o crescimento e a sugestão de dados.

Rabelo alerta para a importância da comunicação no processo de superação do atual modelo de desenvolvimento e para a agudização dos problemas, que aumentaram o interesse e as expectativas em relação ao caráter educativo e mobilizador do jornalismo ambiental" (2002).

A Agenda 21 de Ilhéus deparou-se com os mesmos problemas citados quando se leva em conta a comunicação. No ponto Organização Social, item "Alheamento da população nas questões ambientais", uma das causas desse alheamento está na desinformação sobre a problemática ambiental. Como proposta para os compromissos/ações para a superação dos problemas estão: ações e constituição de mecanismos voltados para a opinião pública, capacitação de líderes e veiculação de temas de preocupação ambiental nos eventos de mobilização de massa.

Outro problema enfocado pelos grupos de trabalho foi " $A$ veiculação precária das questões ambientais pelos meios de comunicação". As consequiências identificadas se manifestam no alheamento da população das questões ambientais, e suas causas estão relacionadas com a baixa ecologização da cultura local; baixa articulação das diversas organizações/instituições ambientais com os meios de comunicação para veiculação de materiais tecnicamente bem elaborados sobre o ambientalismo, e interesses particulares, de caráter econômico, político e social, predominantes na imprensa local, que lhe servem de instrumentos, dificultando a veiculação de questões ambientais quando conflitam com tais interesses. As propostas apontadas foram: melhorar e criar mecanismos de articulações entre os agentes sociais dedicados à área e os meios de comunicação, para veicular temas ambientais de maneira sistemática, e valorizar os meios de comunicação de massa como instrumento de mudança na cultura, para formação de atitudes ambientalistas (GMI, 2002, p.41).

\section{A agenda local em dados}

A partir da compreensão da pesquisa como processo e da concepção da metodologia como fios que se entrecruzam na trajetória a

Comun. Inf., v. 6, n. 2, p.62-74, jul./dez. 2003 
ser percorrida para a apreensão do objeto empírico, apresento algumas estratégias teórico-metodológicas, no intuito de uma aproximação com a produção jornalística sobre o meio ambiente.

Minayo (1994) entende por metodologia "o caminho do pensamento e a prática exercida na abordagem da realidade...", o que implica uma tomada de posição diante de uma série de opções que incidirão na operação realizada no interior da pesquisa, presente desde a definição do problema até a produção e interpretação de dados.

A investigação realizada na Agenda 21 de Ilhéus utilizou a abordagem Qualitativa e, para a técnica, a Análise de Conteúdo. Esse método, segundo Bardin (apud Ungaretti, 1998), é definido como um conjunto de técnicas de análise de comunicações visando obter, por procedimento sistemáticos e objetivos de descrição do conteúdo das mensagens, indicadores (quantitativos ou não) que permitam uma inferência de procedimentos relativos às condições de produção e recepção dessas mensagens. Para Bauer Gaskell (2002), a Análise de Conteúdo trabalha tradicionalmente com materiais textuais escritos, existindo na pesquisa dois tipos de textos: os que são construídos no processo da pesquisa ( transcrição de entrevista, protocolo de observação, etc.) e os que foram produzidos para outra finalidade qualquer (jornais, livros, etc.).

Antes da utilização de qualquer técnica de pesquisa é preciso considerar algumas regras que constituem a Análise de Conteúdo. Uma delas é a regra da representatividade, ou seja, que nada do material delimitado como objeto de pesquisa fique de fora. Outra regra de igual importância é a homogeneidade, na qual o material a ser investigado obedede a critérios precisos de escolha. Por último, a regra da pertinência, em que é observado se as fontes escolhidas possibilitaram, efetivamente, a proposta de análise (Ungaretti, 1998).

Consideradas essas regras partimos para o que Krippendorff (1980, apud Bauer) chama de unidade fisica e unidade temática. No caso do objeto de nossa pesquisa, consideramos a publicação da Agenda 21 de Ilhéus como unidade física e os resultados dos grupos de trabalho, como unidade temática. Consideramos também a técnica leitura flutuante no primeiro contato com o material a ser analisado e o recorte de texto, que se constitui na delimitação das categorias ou unidades temáticas (Ungaretti, 1998).

Comun. Inf., v. 6, n. 2, p.62-74, jul./dez. 2003 
A Agenda de Ilhéus contém cinco capítulos, mas está estruturada fundamentalmente em três: marco teórico, parâmetros referenciais para a ação de desenvolvimento em Ilhéus e conclusões.

O marco teórico contempla a discussão em torno dos conceitos, sobretudo da idéia de sustentabilidade do desenvolvimento e suas dificuldades e possibilidades. Procura, mediante a análise, mostrar os elementos macroestruturais, de contexto amplo, que determinam ou condicionam as ações do micro. Dessa forma, fornece elementos indispensáveis à interpretação das partes na sua vinculação com o todo que as integra, evitando visões fragmentadas dos problemas.

Parâmetros referenciais para a ação de desenvolvimento em Ilhéus - apresenta, duplamente, um diagnóstico da situação. Primeiramente, por meio da localização da cidade no contexto socioeconômico em mudança, desenhando o ambiente que o rodeia e apresentando indicadores de sua posição nesse ambiente. Depois, pelo levantamento de problemas prioritários que entravam o desenvolvimento, identificando suas necessidades, e que vêm sintetizadas em uma tábua de problemas agrupados por linhas temáticas. Após sucinta discussão de causas e conseqüências e de correlações existentes entre os problemas, apresenta soluções para a formulação e propostas concretas de ação para superá-las, agrupadas em 10 linhas temáticas.

As conclusões apresentam uma seleção de ações consideradas prioritárias para que se firmem compromissos de implementação a curto prazo (imediato).

Após a análise, constatamos que a Agenda 21 de Ilhéus contém 65 indicações de problemas e 279 indicações de propostas. No total, a média extraída indica que para cada problema existem mais de quatro propostas.

Com relação ao tratamento dado à comunicação, apresentamos os seguintes dados: de 65 problemas apontados em todos os Grupos de Trabalho, apenas dois explicitam a comunicação como problema, o que corresponde a $3 \%$ dos problemas. Os problemas indicados foram: alheamento da população nas questões ambientais e veiculação precária das questões ambientais pelos meios de comunicação, ambos no GT Organização Social.

As outras inferências sobre comunicação estão registradas na forma de propostas. Num universo de 279 propostas, 13 estão relacionadas com a comunicação, o que corresponde a $4,7 \%$. Dentre elas estão: criação de assessorias de imprensa, campanhas informativas, 
melhor relacionamento com a mídia local e nacional, capacitação técnica em comunicação e uso da Internet.

Outro dado que chamou a atenção foi que entre as 10 linhas temáticas estabelecidas, a comunicação é mencionada como proposta em cinco linhas (Organização Social, Educação, Saúde, Turismo e Degradação Ambiental), isto é, $50 \%$ delas fazem menção à comunicação.

\section{Algumas conclusões}

A que conclusão podemos chegar sobre o modo como se relacionam a Agenda 21 e a comunicação, no caso específico do município de Ilhéus? Assim como a Agenda Global, a local também aponta que a comunicação não pode ser excluída do processo da construção da consciência ambiental. O que tem chamado a atenção neste estudo é que a linha temática que mais indicou propostas e a única que apontou problemas foi a de Organização Social, o que demostra ser esta uma linha aberta, assim como a própria característica interdisciplinar da comunicação. Segundo Berlo (1985), a comunicação influencia o sistema social e o sistema social influencia a comunicação. Nenhum deles pode ser analisado separadamente sem que se distorça a natureza do processo.

Apesar da construção das estatísticas relacionadas acima, um outro dado levantado e que chamou muito a atenção foi localizado no final da Agenda local. O último tópico apresenta 22 propostas estabelecidas como prioritárias para serem cumpridas a curto prazo. A comunicação não é explicitada como prioridade em nenhuma delas.

Concluímos, portanto, que além de a comunicação corresponder somente a $3 \%$ dos problemas e a $4,7 \%$ das propostas, existe, mesmo que em pequenas proporções, um avanço quando se relaciona os problemas do meio ambiente à comunicação e também ao percebê-la como instrumento capaz de minimizar a crise ambiental vigente. A contradição encontrada na elaboração do documento é que, ao mesmo tempo em que se permite entender a comunicação como proposta para os problemas locais, ela própria não aparece como prioridade a curto prazo. Considerando que a comunicação deve ser a mola propulsora de toda mobilização ambiental, é estranho não identificar o problema da comunicação como necessidade imediata.

Comun. Inf., v. 6, n. 2, p.62-74, jul./dez. 2003 
Apesar do relacionamento entre comunicação e Agenda 21 ser incipiente, haveremos de concordar com Rabelo (2001) quando afirma que, a despeito da gravidade e complexidade da crise ambiental contemporânea, sinais de mudança surgem. E o que mais impressiona e anima são os que vêm das esferas locais, mas nem sempre de iniciativas espontâneas.

\section{Abstract}

The Conference of the United Nations on Environment and Development, carried through in June 1992, also known as RIO-92, approved important agreements, among them, Agenda 21. The Agenda is a letter of commitments, aiming at the sustainable development, elaborated in the scopes federal, state and municipal, between government and society. In Ilhéus, south region of the state of Bahia, the elaboration of Agenda 21 started to be discussed in the end 1997 , having its conclusion in September 1998. The objective of this work is to analyze qualitatively the text of Agenda 21 of Ilhéus, trying to identify the problems and the solutions purposed, related to the Social Communication.

Key words: communication; environment; agenda 21.

\section{Referências}

ADEODATO, S. ONGs afirmam que governos adotaram mas não assumiram a Agenda 21. São Paulo: Gazeta Mercantil, jun. 1993.

BAUER, M. W.; GASKELL, G. (Org.). Pesquisa quantitativa com texto, imagens e som. Tradução de Pedrinho A. Guareschi. Petrópolis: Vozes, 2002.

BERLO, D. $O$ processo da comunicação: introdução à teoria e à prática. Tradução de Jorge Arnaldo Fontes; SILVA, I. B. 5. ed. São Paulo: Martins Fontes, 1985.

BARROS, A. T. Ecologia em revistas: análise de conteúdo das revistas Veja e Istoé nas décadas de 1970 a 1990. Revista Ciberespaço, [S.1.], n. 4, 2001. Disponível em: <http://www.uff.br/mestcii/rep.htm. Acesso em: 29 de abr. 2003.

CASTELLS, M. A era da informação: economia, sociedade e cultura. O Poder da Identidade. Tradução de Klauss Brandini Gerhardt. São Paulo: Paz e Terra, v. $2,1999$.

COMISSÃO MUNDIAL SOBRE MEIO AMBIENTE E DESENVOLVIMENTO. Nosso Futuro Comum. 2. ed. Rio de Janeiro: FGV, 1991. 430 p.

GORGULHO, S. O Papel da mídia na questão ambiental. In: Folha do Meio Ambiente. Brasília, DF, ano 13, n. 132, nov. 2002.

GOVERNO MUNICIPAL DE ILHÉUS. Agenda 21 de Ilhéus: rumo ao século XXI. Ilhéus: Editora da Universidade Livre do Mar e da Mata, 2002. 103 p.

LEIS, H. R. et al. Meio ambiente, desenvolvimento e cidadania: desafio para as ciências sociais. São Paulo: Cortez, 1998.

Comun. Inf., v. 6, n. 2, p.62-74, jul./dez. 2003 
MINISTÉRIO DO MEIO AMBIENTE. Agenda 21 Brasileira: ações prioritárias. Brasília: MMA, 2000.

MINISTÉRIO DO MEIO AMBIENTE. Subsídios à elaboração da Agenda 21 Brasileira: cidades sustentáveis. Brasília: MMA, 2000a.

MINAYO, M. C. S. (Org.). et al. Pesquisa social: teoria, método e criatividade. Petropolis: Vozes, 1994.

RABELO, D. C. Comunicação e mobilização social: aAgenda 21 local de Vitória (ES). 2002. Tese (Doutorado em Comunicação Social) - Universidade Metodista de São Paulo. São Bernardo do Campo, 2002.

. A Competência comunicativa dos especialistas nos espaços de negociação ambiental: estudo da Agenda 21 local de Vitória (ES). In: CONGRESSO BRASILEIRO DE COMUNICAÇÃO, 24., 2001, Campo Grande. Anais... Campo Grande: Intercom, set. 2001.

RAMOS, L. F.A. Meio ambiente e meios de comunicação. São Paulo: Annablume, 1995.

STARKE, L. Sinais de Esperança: lutando por nosso futuro comum. Rio de Janeiro: FGV, 1992. p. 119-138.

UNGARETTI, W. N. Empresariado e ambientalismo: uma análise de conteúdo da Gazeta Mercantil. São Paulo: Annablume, 1998.

VIOLA, E. O. Movimento ambientalista no Brasil (1971-1991): da denúncia e conscientização pública para a institucionalização e desenvolvimento sustentável. In: GOLDENBERG, M. (Org.). Ecologia, ciência e política. Rio de Janeiro: Revan, 1992.p. 54-61.

VILLAR, R. Jornalismo Ambiental: evolução e perspectivas. [S.l.: s.n], 2003. Disponível em: $<$ http://www.agirazul.com.br/artigos/jorental.htm $>$. Acesso em: 29 abr. 2003.

Comun. Inf., v. 6, n. 2, p.62-74, jul./dez. 2003 